Article

\title{
Simplified LC-MS Method for Analysis of Sterols in Biological Samples
}

\author{
Cene Skubic ${ }^{1}$, Irena Vovk ${ }^{2}$, Damjana Rozman ${ }^{1}$ and Mitja Križman ${ }^{2, *}$ \\ 1 Center for Functional Genomics and Bio-Chips, Institute of Biochemistry, Faculty of Medicine, \\ University of Ljubljana, Zaloška cesta 4, SI-1000 Ljubljana, Slovenia; cene.skubic@mf.uni-lj.si (C.S.); \\ damjana.rozman@mf.uni-lj.si (D.R.) \\ 2 Department of Food Chemistry, National Institute of Chemistry, Ljubljana, Hajdrihova 19, \\ SI-1000 Ljubljana, Slovenia; irena.vovk@ki.si \\ * Correspondence: mitja.krizman@ki.si; Tel./Fax: +386-1-4760-266
}

Academic Editors: Vassilios Roussis and Efstathia Ioannou Received: 13 August 2020; Accepted: 8 September 2020; Published: 9 September 2020

\begin{abstract}
We developed a simple and robust liquid chromatographic/mass spectrometric method (LC-MS) for the quantitative analysis of 10 sterols from the late part of cholesterol synthesis (zymosterol, dehydrolathosterol, 7-dehydrodesmosterol, desmosterol, zymostenol, lathosterol, FFMAS, TMAS, lanosterol, and dihydrolanosterol) from cultured human hepatocytes in a single chromatographic run using a pentafluorophenyl (PFP) stationary phase. The method also avails on a minimized sample preparation procedure in order to obtain a relatively high sample throughput. The method was validated on 10 sterol standards that were detected in a single chromatographic LC-MS run without derivatization. Our developed method can be used in research or clinical applications for disease-related detection of accumulated cholesterol intermediates. Disorders in the late part of cholesterol synthesis lead to severe malformation in human patients. The developed method enables a simple, sensitive, and fast quantification of sterols, without the need of extended knowledge of the LC-MS technique, and represents a new analytical tool in the rising field of cholesterolomics.
\end{abstract}

Keywords: cholesterol; LC-MS; sterol intermediates; cholesterol synthesis; pentafluorophenyl; PFP

\section{Introduction}

Cholesterol is the most abundant sterol molecule in animal cells. It is an important part of the cell membrane, where also the majority of cholesterol is located. In cell membranes, cholesterol is responsible for proper physical properties like fluidity and rigidness and is a part of lipid rafts [1]. Besides its role in membranes, cholesterol is the precursor for bile acids and oxysterols, and its synthesis metabolites are vitamin D precursors. Cholesterol is synthesized in the first step from acetyl-CoA through a mevalonate pathway to squalene. The mevalonate pathway of synthesis is well known and statins, widely used drugs for treating hypercholesterolemia, affect the rate-limiting enzyme HMG-CoA reductase which transforms HMG-CoA to mevalonate. Lanosterol is the first molecule in the post-squalene part of cholesterol synthesis and the first molecule with a characteristic sterol ring [2,3]. From lanosterol on, the synthesis is separated into the proposed Bloch and Kandutsch-Russell pathways, schematically represented in Ačimovič et al. [3]. The final step in the Bloch branch is the conversion of desmosterol to cholesterol by sterol- $\Delta 24$-reductase (DHCR24). However, because all sterols intermediated downstream from lanosterol have a double bond on position C24, DHCR24 can act already on lanosterol which is proposed in the Kandutsch-Russell branch. In this case, all intermediates from 24,25-dihydrolanosterol to 7-dehydrocholesterol contain a saturated side chain and cholesterol is synthesized in the last step from 7-dehydrocholesterol by the DHCR7 enzyme. DHCR24 can theoretically transform any cholesterol synthesis intermediate from lanosterol on; the two 
branches cannot be treated separately. In both pathways combined, there are at least 20 different sterol molecules, from which many of them share the same molecule mass and have a very similar structure [4]. However, the theoretical number of sterol intermediates from lanosterol to cholesterol is much higher [5] but not all of these sterols have been detected in biological systems.

Cholesterol synthesis is a housekeeping pathway and any abnormalities in the late part of synthesis usually lead to accumulation of sterol intermediates which results in severe malformations in humans [6]. Examples of diseases include desmosterolosis (desmosterol accumulation), lathosterolosis (lathosterol accumulation), Conradi-Huenermann-Happle syndrome (zymosterol accumulation), Smith-Lemli-Opitz syndrome, or Antley-Bixler syndrome (lanosterol and 24,25-dihydrolanosterol accumulation) [6,7]. In recent years, studies have shown that sterol intermediates, apart from being cholesterol precursors, have other important physiological functions, like a role in spermatogenesis, oligodendrocyte remyelination, and activations of nuclear receptors [8-10]. Due to the utmost importance for further cholesterol metabolism research, a new research field has arisen, named "cholesterolomics" [11]. Cholesterolomics can be regarded as the identification and quantification of cholesterol, its post squalene precursors, and metabolites of cholesterol and of its precursors, in biological samples. To decipher the physiological function of sterol intermediates and detect accumulating sterols in different pathologies for a given situation or experimental setup, the need for a customized analytical methodology might therefore arise (as in the given case), preferably providing a simple and straightforward procedure.

Chromatographic analysis of sterols can be accomplished in a variety of ways. Since many sterols share the same molecular mass and have a very similar structure, discriminating mass spectrometric detection is challenging or even impossible, especially with compounds which are prone to abundant fragmentation [12]. Likewise, a good chromatographic resolution can also be problematic due to their very similar chromatographic behavior. Similarly, a situation, albeit a bit less challenging, can also be encountered when oxysterols, slightly more polar analytes, are analyzed on their own. As a result, analytics of oxysterols alone have been a subject of substantial research as well [13]. Traditionally, gas chromatography (GC) has been used as the technique of choice when an improved resolution in sterol analysis was needed. Sterol detection in GC analysis can be done by either flame-ionization (FID) or mass spectrometric (MS) detection. Sterols can be analyzed by GC in both underivatized [14] or derivatized form $[15,16]$. In the latter case, there is some improvement in chromatographic resolution. However, the derivatization step involves a few drawbacks. It is not only much more labor-intensive but also introduces other sources of error into the analytical procedure. Nonetheless, the GC-MS technique is also inherently less sensitive compared to LC-MS. Therefore, the analysis of sterols by high-performance liquid chromatography (HPLC) is a valid and practical alternative. LC-MS has become the technique of choice also in the field of sterol analytics, steadily displacing established techniques like gas chromatography [17].

There are a number of published HPLC methods for sterol analysis. Since sterols have a low inherent UV detection response, UV detection is used only in cases when analyte concentrations are relatively high. In cases when minor sterol compounds, e.g., sterol intermediates, need to be analyzed, MS detection is likely to be the only viable option. Since sterols are not ionizable compounds, electrospray ionization (ESI) should not be a sensible option in MS detection. However, under some very narrow conditions, sterols can be ionized in the ESI source in the form of adducts, as evidenced in a few publications [18-20]. Unfortunately, under most other chromatographic conditions, ESI ionization is not a good option. In most other cases, as in the presented work, atmospheric-pressure chemical ionization (APCI) is the most common ionization technique for sterols [18,21-23]. They can also be successfully ionized under atmospheric-pressure photo-ionization (APPI) conditions when such an ion source is available [24]. For a variety of reasons, mainly practical ones, most of these methods use reversed-phase columns, and predominantly the octadecyl-silica type of stationary phase $[17,23,25,26]$. Many of them involve gradient elution in order to improve selectivity. Low column temperatures are 
also commonly employed to accentuate the minute differences among individual sterols and therefore enhance the overall chromatographic resolution.

The aim of our study was to develop a simple and robust LC-MS method that would allow the separation and quantification of 10 structurally similar sterols from cholesterol synthesis in a single chromatographic run. The LC-MS method in the presented work provides sterol separation using a less common column phase, namely pentafluorophenyl (PFP) stationary phase, and avails on a different set of retention mechanisms usually found in common reversed phases [27].

\section{Results and Discussion}

\subsection{Chromatographic Separation and Detection}

As a starting point, we deliberately avoided procedures involving sample derivatization [28], due to the drawbacks mentioned previously. Therefore, we opted to use a well-known and proven methodology, like the one published by McDonald et al. (2007) [26], since it is capable of resolving most of the analytes of interest in the underivatized form, and using similar instrumentation. However, the largest pitfall is a relatively poor inherent sensitivity of this method for some of the compounds of interest, e.g., zymosterol, desmosterol, and lathosterol [26]. Additionally, we have not obtained satisfactory separation for some other compounds of interest, not covered by this paper. Even later developments from the same group [23] gave no satisfactory separation between lathosterol and cholesterol, the former being an important parameter in the analysis of biological samples. Therefore, we opted to develop a custom methodology for sterols alone, without involving the analytics of oxysterols. The goal was also to improve sensitivity as much as possible, in order to avoid the need for further sample purification and/or concentration.

We were able to chromatographically separate 10 sterols using a pentafluorophenyl stationary phase column and find specific multiple reaction monitoring mode (MRM) transitions for their quantification (Figure 1). To ensure successful chromatographic separation, the analysis run time is rather long, namely $30 \mathrm{~min}$, in order to obtain sufficient resolution, as is in the case of most similar published methods. The relatively long run time is also partially due to the isocratic elution used, but in turn, there are no issues with long column re-equilibration times, as it would be in the case of gradient elution. Being isocratic, the method can also be scaled up for preparative separation purposes without gradient elution-associated difficulties. All sterols elute in the time interval between 15 and $27 \mathrm{~min}$. The most challenging to separate were zymosterol, 24-dehydrolathosterol, and desmosterol, which all have a molecular weight of 384.6 and the same MRM transition (Table 3) of 367/215. A good chromatographic separation is therefore a must in order to separately detect and quantify each of these sterols. A similar problem had to be solved for the successful separation of zymostenol and lathosterol (Figure 1) with MRM 369/215 and cholesterol in the case of sample analysis (Figure 2). 


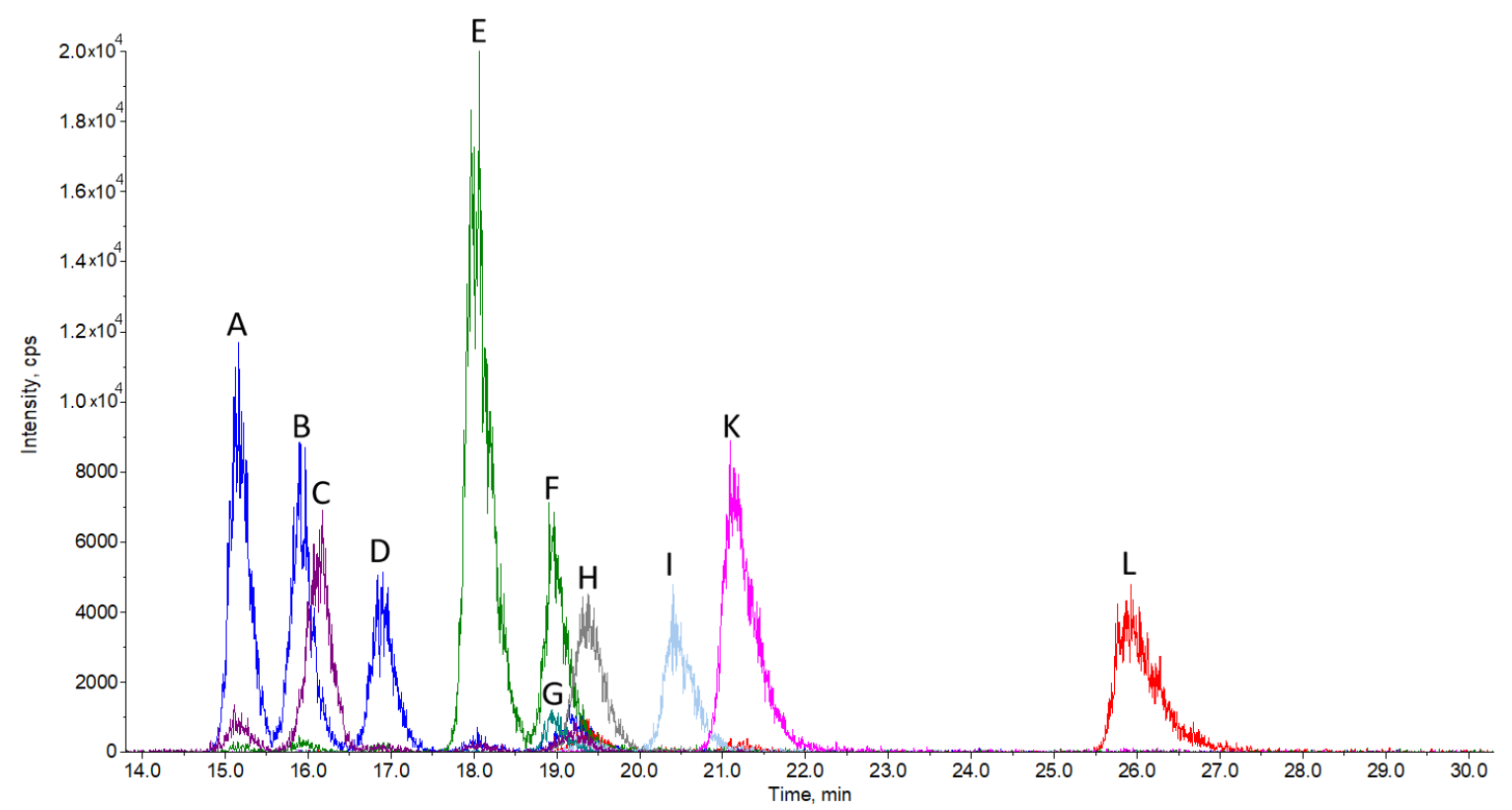

Figure 1. Chromatogram of sterol standards: zymosterol (A), 24-dehydrolathosterol (B), 7-dehydrodesmosterol (C), desmosterol (D), zymostenol (E), lathosterol (F), lathosterol-d7 (G), FFMAS $(\mathrm{H})$, TMAS $(\mathrm{I})$, lanosterol $(\mathrm{K})$, and dihydrolanosterol $(\mathrm{L})$. The peak $(\mathrm{J})$ is dedicated to cholesterol and is not presented in this chromatogram. Cholesterol is not assayed, since its concentration is several orders of magnitude larger than other sterols. Cholesterol was assayed using a separate analytical method. Separation conditions are described in Section 3.3 LC-MS Analysis.

The mobile phase consisting of water, methanol, and 1-propanol, in combination with the pentafluorophenyl stationary phase (PFP), proved to be a good combination since selectivity and the overall resolution was even slightly improved at higher column temperatures, which is usually not the case in most HPLC methodologies used in sterol analysis. The validation of the method was done on different concentrations of standards and in different times of injection (as described in Materials and Methods). Validation data are represented in Table 1 and described in Section 3.4.

Table 1. Validation data for sterol intermediates for all measured sterols.

\begin{tabular}{cccccccc}
\hline Sterols & $\begin{array}{c}\text { Accuracy } \\
\mathbf{( \% )}\end{array}$ & $\begin{array}{c}\text { Repeatability } \\
\text { (\% RSD) }\end{array}$ & $\begin{array}{c}\text { Regression } \\
\text { Coefficient }\end{array}$ & $\begin{array}{c}\text { Stability } \\
\mathbf{4 8} \mathbf{h} \mathbf{( \% )}\end{array}$ & $\begin{array}{c}\text { LOQ } \\
\text { (ng/mL) }\end{array}$ & $\begin{array}{c}\text { LOD } \\
\text { (ng/mL) }\end{array}$ & $\begin{array}{c}\text { S/N } \\
\mathbf{( 1 2 5} \mathbf{~ n g} / \mathbf{m L})\end{array}$ \\
\hline Zymosterol & 105.0 & 7.5 & 0.9999 & 86.6 & 90.6 & 27.2 & 13.8 \\
Dihydrolanosterol & 97.9 & 4.2 & 0.9999 & 96.2 & 148.8 & 44.6 & 8.4 \\
Zymostenol & 106.4 & 3.5 & 0.9999 & 95.2 & 78.1 & 23.4 & 16.0 \\
FFMAS & 86.5 & 6.1 & 0.9999 & 82.5 & 178.5 & 53.6 & 7.0 \\
TMAS & 87.2 & 4.3 & 0.9998 & 82.2 & 187.7 & 56.3 & 6.7 \\
Lanosterol & 95.7 & 5.8 & 0.9998 & 92.5 & 115.7 & 34.7 & 10.8 \\
7-dehydrodesmosterol & 109.7 & 7.4 & 0.9996 & 88.3 & 152.4 & 45.7 & 8.2 \\
24-dehydrolathosterol & 103.1 & 9.4 & 0.9997 & 93.0 & 96.9 & 29.1 & 12.9 \\
Desmosterol & 96.1 & 4.5 & 0.9997 & 85.4 & 151.5 & 45.5 & 8.3 \\
Lathosterol & 101.2 & 5.2 & 0.9997 & 89.4 & 183.8 & 55.1 & 6.8 \\
\hline
\end{tabular}

LOD, limit of detection; LOQ, limit of quantitation; $\mathrm{S} / \mathrm{N}$, signal to noise ratio. Linearity was tested in the concentration range from 67.5 to $5000 \mathrm{ng} / \mathrm{mL}$ Data validation method is explained in Section 3.4 Quantitation, Accuracy, Repeatability, Linearity, and Stability. 


\subsection{Sample Analysis}

To test the LC-MS method on biological samples, we isolated sterols from cell cultures as described in the sample preparation. We used hepatocellular cancer cell lines HepG2 and HepG2 with CRISPR-Cas9-generated deletion in the DHCR24 enzyme. In wild type HepG2 cells, we were able to detect (Figure 2) and quantify (Figure 3 and Table 2) eight sterol intermediates. The concentration of sterol FF-MAS in these cells was too low for detection, which is consistent with previously observed FF-MAS concentrations in liver tissue [29,30]. In HepG2 DHCR-KO, all measured sterols are statistically different compared to non-modified HepG2 cells (Table 3). Due to an inactive DHCR24 enzyme, sterol intermediates from the Bloch branch of cholesterol synthesis accumulate in very high concentrations and sterols from the Kandutsch-Russell branch are absent. In the DHCR-KO sample, we also detected an unknown sterol peak ( $X$ on Figure 2d) with retention time of 14.15 min and MRM 365/199. This could be one of the sterols from the Bloch pathway for which commercial standards are not available or a sterol intermediate that is normally not present in cells and is the result of further enzymatic transformation.

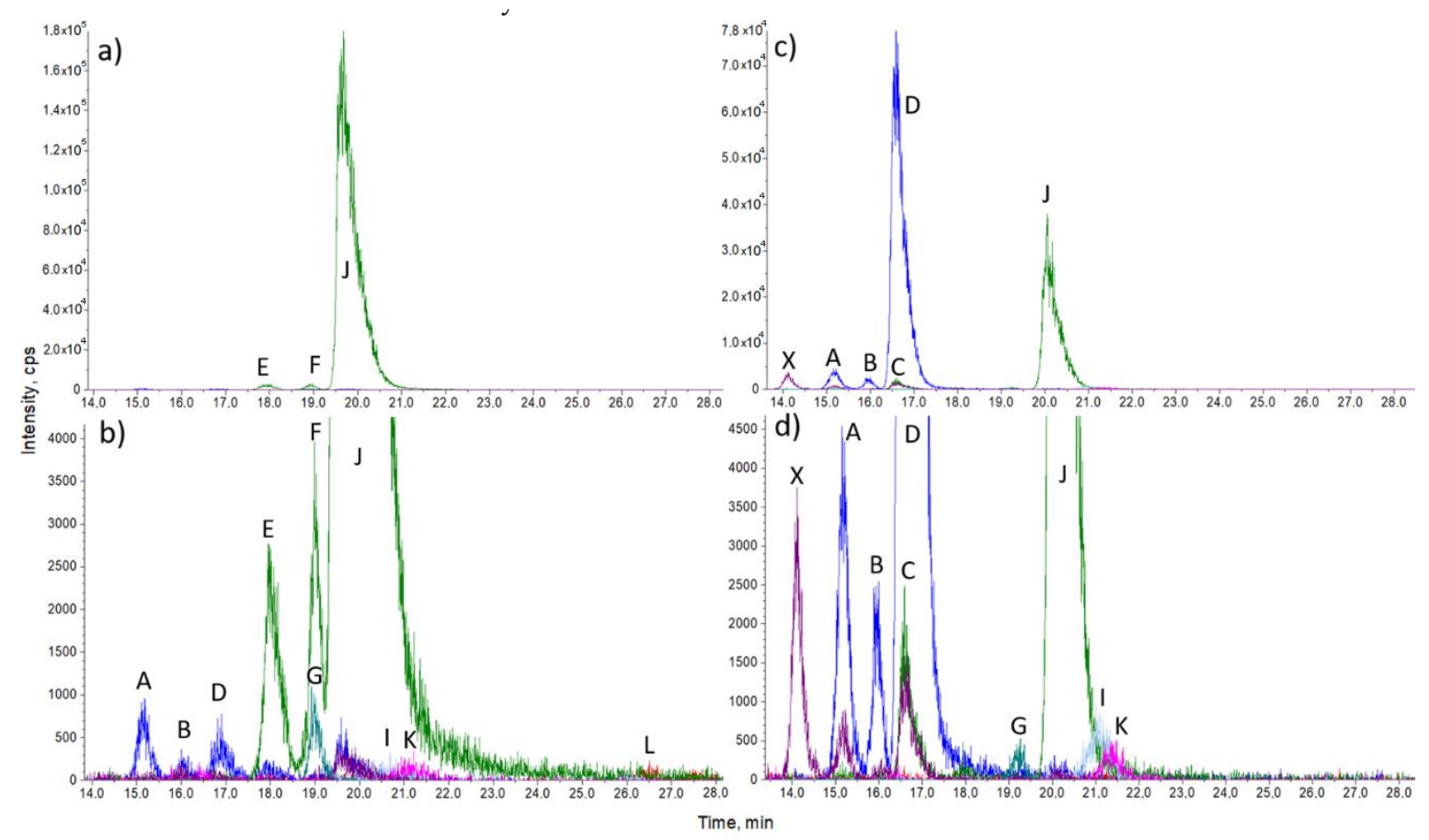

Figure 2. Representative chromatograms of sterols isolated from native HepG2 cells (a,b) and HepG2 DHCR KO cells (c,d). Each chromatogram is presented in two magnifications to account for a higher quantity of cholesterol compared to intermediate sterols $(\mathbf{a}, \mathbf{b})$ or desmosterol and cholesterol compared to other sterols (c,d). Zymosterol (A), 24-dehydrolathosterol (B), 7-dehydrodesmosterol (C), 7-desmosterol (D), zymostenol (E), F-lathosterol (F), lathosterol-d7 (G), TMAS (I), holesterol (J), lanosterol (K), dihydrolanosterol (L), and an unknown peak with the MRM of 365/199 (X). All peaks with the same MRM transition (A, B, D and E, F, J) are chromatographically separated. Peak of cholesterol is depicted for illustrative purpose only. 

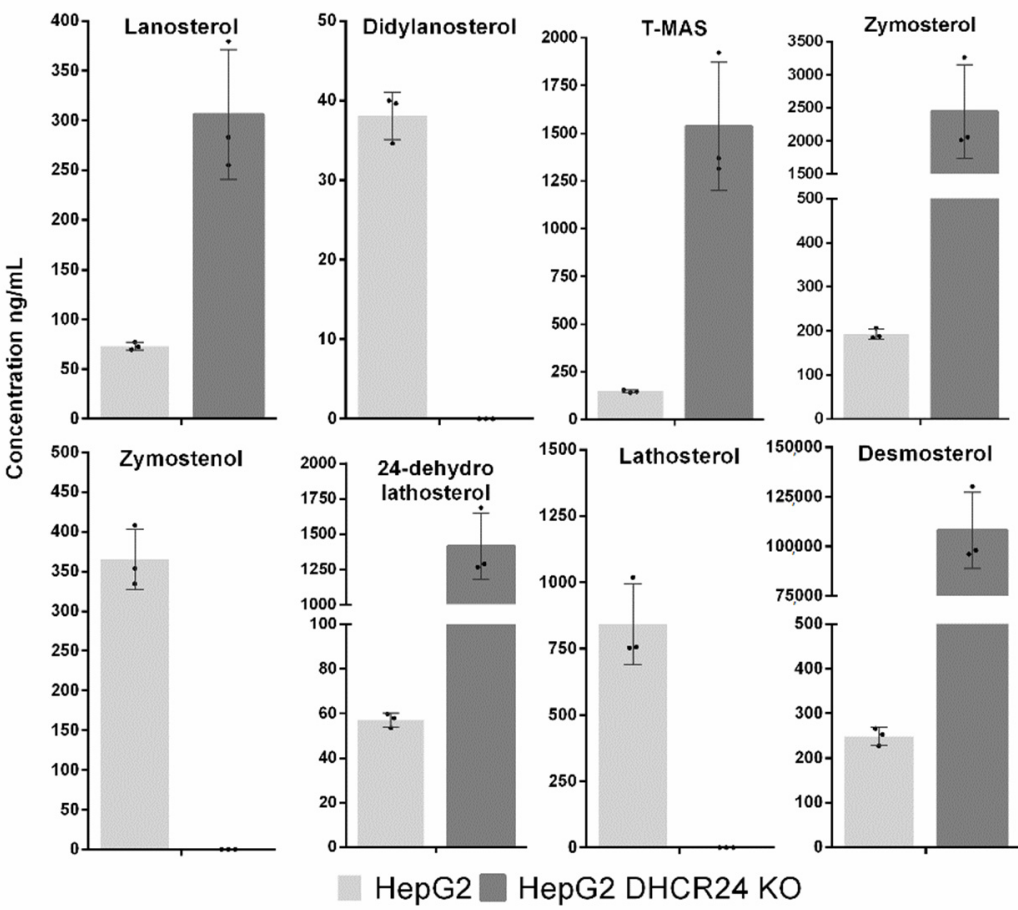

Figure 3. Concentrations of sterol intermediates isolated from HepG2 and HepG2 DHCR-KO cell lines. All concentrations are calculated as $\mathrm{ng} / \mathrm{mL}$ per $10^{7}$, to normalize sterol concentration based on the number of counted cells. All data are represented as mean with SD, black dots represent individual measurements.

Table 2. Concentration of sterols isolated from HepG2 and HepG2 DHCR24 KO cell cultures.

\begin{tabular}{|c|c|c|c|c|c|}
\hline \multirow{3}{*}{ Sterol Measured } & \multicolumn{2}{|c|}{$\begin{array}{c}\text { HepG2 } \\
n=3\end{array}$} & \multicolumn{2}{|c|}{$\begin{array}{c}\text { HepG2 DHCR24 KO } \\
n=3\end{array}$} & \multirow{3}{*}{$\begin{array}{l}\text { Statistical } \\
\text { Significance with } \\
\text { Unpaired } t \text {-Test }\end{array}$} \\
\hline & \multicolumn{4}{|c|}{ Concentration } & \\
\hline & Mean (ng/mL) & SD & Mean (ng/mL) & SD & \\
\hline Zymosterol & 192.8 & 11.7 & 2446.1 & 707.1 & $* * *$ \\
\hline Dihydrolanosterol & 38.1 & 3.0 & 0.0 & 0.0 & $* * * *$ \\
\hline Zymostenol & 365.5 & 38.1 & 25.8 & 23.5 & $* *$ \\
\hline T-MAS & 148.5 & 7.6 & 1535.9 & 335.6 & $* *$ \\
\hline Lanosterol & 73.1 & 3.8 & 305.9 & 65.1 & $* *$ \\
\hline 7-dehydrodesmosterol & 36.0 & 2.3 & 1411.6 & 236.3 & $* * *$ \\
\hline 24-dehydrolathosterol & 57.0 & 3.2 & 1414.0 & 236.8 & $* * *$ \\
\hline Desmosterol & 248.7 & 19.8 & 108156.4 & 19170.1 & $* * *$ \\
\hline Lathosterol & 842.9 & 152.4 & 0.0 & 0.0 & $* * *$ \\
\hline
\end{tabular}

Mean and SD were calculated from concentrations measured in three biological replicates (details in 4.2 Sample preparation). Statistical significance comparing HepG2 and HepG2 DHCR24 KO with unpaired $t$-test * $p<0.05$, ${ }_{* *}^{*} p<0.01,{ }^{* * *} p<0.001,{ }^{* * * *} p<0.0001$.

\section{Materials and Methods}

\subsection{Materials}

All sterol standards (listed in Table 3) were bought from Avanti Polar Lipids (Alabaster, AL, USA), except cholesterol, which is from Merck (Darmstadt, Germany). Chloroform, cyclohexane, 1-propanol, and methanol (all LC-MS grade) were purchased from Honeywell (Charlotte, NC, USA). Dulbecco's modified Eagle's medium (DMEM), Penicillin-Streptomycin (P/S), Trypsin, and Fetal Bovine Serum (FBS) were bought from Merck (Darmstadt, Germany). 


\subsection{Sample Preparation}

\subsubsection{Isolation and Culture of Human Hepatocytes}

Here, $1 \times 10^{6}$ of HepG2 and HepG2 with DHCR24 deletion (ordered from Synthego, Menalo Park, CA, USA) cells were plated on a T75 culture flask for each sterol isolation. Cells were plated in classic DMEM medium with 10\% FBS and 1\% P/S. After $24 \mathrm{~h}$, the cell medium was changed with DMEM with $2 \% \mathrm{FBS}$ and $1 \% \mathrm{P} / \mathrm{S}$ to lower the cholesterol concentration in the medium and upregulate cholesterol synthesis in the cells. After $48 \mathrm{~h}$, cells were washed two times with Phosphate-buffered saline (PBS) and detached using $1 \mathrm{~mL}$ of Trypsin. Detached cells were resuspended in $5 \mathrm{~mL}$ of DMEM without FBS and transferred to a $15 \mathrm{~mL}$ glass vial with a Polytetrafluoroethylene (PTFE) cap. An amount of $50 \mu \mathrm{L}$ of cells was used for cell counting on an Adam Automatic Cell Counter (Alpha Metrix Biotech GmbH, Rödermark, Germany). There were between 0.9 and $2.2 \times 10^{7}$ cells counted. The rest of the cells were pelleted by centrifugation at $700 \mathrm{rpm}$ for $5 \mathrm{~min}$ and washed one more time with PBS.

\subsubsection{Sterol Isolation}

Folch reagent ( $5 \mathrm{~mL} ; 66 \%$ chloroform, 33\% methanol) was added to each cell pellet and vortexed for $60 \mathrm{~s}$. At this step, $200 \mathrm{ng}$ of internal standard lathosterol-D7 was added and samples were incubated for $2 \mathrm{~h}$ at room temperature, with shaking. After incubation, Folch reagent was evaporated using a vacuum centrifuge (Eppendorf Concentrator 5301, Eppendorf, Hamburg, Germany) at $45{ }^{\circ} \mathrm{C}$, followed by hydrolysis with $1 \mathrm{~mL}$ of hydrolysis solution $\left(8 \mathrm{~g} \mathrm{NaOH}+20 \mathrm{~mL} \mathrm{H}_{2} \mathrm{O}+180 \mathrm{~mL} 99.5 \%\right.$ ethanol) at $65{ }^{\circ} \mathrm{C}$ with shaking. Extraction was made using $0.5 \mathrm{~mL} \mathrm{H}_{2} \mathrm{O}$ and $3 \mathrm{~mL}$ of cyclohexane centrifugation on $3500 \mathrm{rpm}$ for $10 \mathrm{~min}$ (Eppendorf 5810 R, Eppendorf, Hamburg, Germany). The upper phase was transferred to a new $15 \mathrm{~mL}$ vial. Extraction was repeated one more time on the remaining sample with only $3 \mathrm{~mL}$ of cyclohexane. The upper phase was pooled and evaporated using a vacuum centrifuge at $45^{\circ} \mathrm{C}$. Samples were resuspended in $300 \mu \mathrm{L}$ of methanol and transferred to HPLC for analysis.

\subsection{LC-MS Analysis}

Chromatographic separation was done on a Shimadzu Nexera XR HPLC (Shimadzu, Kyoto, Japan) under isocratic conditions, with a mobile phase of methanol/1-propanol/water/formic acid (80:10:10:0.02 $\%, v / v / v / v)$ and flow of $150 \mu \mathrm{L} / \mathrm{min}$. Five microliters of standard or sample solutions was injected. Two Phenomenex Luna $3 \mu \mathrm{m}$ PFP (pentafluorophenyl) columns (Phenomenex, Torrance, CA, USA) connected in series with dimensions $100 \times 2 \mathrm{~mm}$ and $150 \times 2 \mathrm{~mm}$ were used for separation, and the oven temperature was set to $40^{\circ} \mathrm{C}$. For detection, a SCIEX Triple Quad ${ }^{\mathrm{TM}} 3500$ mass spectrometer (AB Sciex LLC, Redwood City, CA, USA) was used, with APCI ionization in multiple reaction monitoring mode (MRM). Pairs of parent/daughter ions used in MRM detection have been selected based on daughter ion intensity and the observed signal to noise ratio in order to obtain the maximum sensitivity given the experimental conditions used. Ion source temperature was $350{ }^{\circ} \mathrm{C}$, collision gas was 4 , declustering potential was $140 \mathrm{~V}$, curtain gas was 20, entrance potential was $10 \mathrm{~V}$, cell exit potential was $6 \mathrm{~V}$, and collision energy was $45 \mathrm{~V}$. Other detection conditions are displayed in Table 3. 
Table 3. MS detection conditions and retention times.

\begin{tabular}{|c|c|c|c|c|c|}
\hline Trivial Name & $\begin{array}{c}\text { Avanti Polar } \\
\text { Lipids Number * }\end{array}$ & Chemical Name & $\begin{array}{l}\text { Molar } \\
\text { Mass }\end{array}$ & MRM * & $t_{R}(\min )$ \\
\hline Lanosterol & $700063 \mathrm{P}$ & 8,24-lanostadien-3 $\beta$-ol & 426.72 & $409 / 191$ & 21.4 \\
\hline $\begin{array}{l}\text { Dihydro } \\
\text { lanosterol }\end{array}$ & $700067 \mathrm{P}$ & 24,25-dihydrolanosterol & 428.73 & $411 / 191$ & 26.3 \\
\hline FFMAS & $700077 \mathrm{P}$ & $\begin{array}{l}\text { 14-demethyl-14- } \\
\text { dehydrolanosterol }\end{array}$ & 410.68 & $393 / 214$ & 19.5 \\
\hline TMAS & $700073 \mathrm{P}$ & $\begin{array}{l}\text { 4,4-dimethylcholest- } \\
\text { 8(9),24-dien-3ß-ol }\end{array}$ & 412.69 & $395 / 243$ & 20.7 \\
\hline Zymosterol & $700068 \mathrm{P}$ & $\begin{array}{c}5 \alpha \text {-cholesta-8,24-dien- } \\
3 \beta \text {-ol }\end{array}$ & 384.64 & $367 / 215$ & 15.3 \\
\hline Zymostenol & $700118 \mathrm{P}$ & $5 \alpha$-cholest-8-en-3 $\beta$-ol & 386.65 & $369 / 215$ & 18.2 \\
\hline $\begin{array}{l}\text { 24-dehydro } \\
\text { lathosterol }\end{array}$ & $700114 \mathrm{P}$ & $\begin{array}{c}5 \alpha \text {-cholesta-7,24-dien- } \\
3 \beta \text {-ol }\end{array}$ & 384.64 & $367 / 215$ & 16.0 \\
\hline lathosterol & $700069 \mathrm{P}$ & $5 \alpha$-cholest-7-en- $3 \beta$-ol & 386.65 & $369 / 215$ & 19.1 \\
\hline $\begin{array}{l}\text { 7-dehydro } \\
\text { desmosterol }\end{array}$ & $700138 \mathrm{P}$ & 7-dehydrodesmosterol & 382.62 & $365 / 199$ & 16.3 \\
\hline Desmosterol & $700060 \mathrm{P}$ & $\begin{array}{l}\text { 3ß-hydroxy-5,24- } \\
\text { cholestadiene }\end{array}$ & 384.64 & $367 / 215$ & 16.9 \\
\hline Lathosterol-d7 & $700056 \mathrm{P}$ & $\begin{array}{c}5 \alpha \text {-Cholest-7-en-3 } \beta \text {-ol }(25,26, \\
26,26,27,27,27-d 7)\end{array}$ & 393.70 & $376 / 215$ & 19.2 \\
\hline Cholesterol & Merck (C3045) & Cholest-5-en-3 $\beta$-ol & 386.70 & $369 / 215$ & 19.8 \\
\hline
\end{tabular}

* All additional data about standards, including molecular formula, are available on the Avanti Polar Lipids web page (https://avantilipids.com/).

\subsection{Quantitation, Accuracy, Repeatability, Linearity, and Stability}

Injection precision was determined by three injections of a working standard solution containing each sterol standard (except for cholesterol) at $250 \mathrm{ng} / \mathrm{mL}$. Since the cholesterol concentration in samples is significantly higher than other sterols, it was not tested in the method validation as other sterols. Standard solutions with the same sterol concentrations have also been used for the quantification of sterols in samples using the external standard method. Repeatability was assessed by preparing the selected cell culture sample in three replicates using the same sample preparation procedure. Intermediate precision was tested on the same set of samples by analyzing them on three consecutive days. Accuracy has been tested by spiking samples with selected standards and subjecting the spiked samples to the sample preparation procedure, analyzing them, and calculating the recovery. Linearity for all sterols (except for cholesterol) has been tested in the concentration range from 67.5 to $5000 \mathrm{ng} / \mathrm{mL}$. Limits of detection (LOD) and quantitation (LOQ) have been extrapolated from signal to noise measurements obtained for standard solutions used in the linearity tests. Stability was tested in the period of $48 \mathrm{~h}$ on selected samples kept refrigerated at $4{ }^{\circ} \mathrm{C}$ in the dark.

\section{Conclusions}

In conclusion, we developed a simplified LC-MS method for the detection and quantification of 10 sterols from the late part of cholesterol synthesis using commercially available sterol standards. We were able to chromatographically separate the sterol molecules with the same mass and MRMs. We confirmed our LC-MS method on sterols isolated from HepG2 cell culture samples. Our method can be used also for the quantification of sterols using tissue or serum/plasma samples with minor changes in the isolation protocols described $[16,23]$ or using commercially available kits like MAK175 (Merck, Darmstadt, Germany). Our LC-MS is superior to the previously described GC-MS method [16] and is also able to resolve, in a better way, some of the sterols, like cholesterol and lathosterol, which are not sufficiently resolved by previously published methods. Its advantages are no need for sample derivatization, good linearity, and the possibility to obtain sterol quantification with isolation in less than $24 \mathrm{~h}$, within a single LC-MS run. For more detailed sterol and oxysterol analyses, methods like those 
described in McDonald et al. can be used $[23,26]$ alone or in combination with our chromatographic method. Being isocratic, the method can also be easily adapted for preparative chromatography.

Author Contributions: Conceptualization, M.K. and D.R.; methodology, M.K.; validation, C.S. and M.K.; formal analysis, C.S and M.K.; investigation, M.K.; resources, D.R. and I.V.; writing-original draft preparation, C.S. and M.K.; writing-review and editing, I.V. and D.R.; visualization, C.S.; supervision, D.R. and M.K.; project administration, I.V. and D.R.; funding acquisition, D.R. All authors have read and agreed to the published version of the manuscript.

Funding: This work was supported by the Slovenian Research Agency (ARRS) program grants P1-0390 and P1-0005, and research project J1-9176.

Acknowledgments: The authors acknowledge the financial support from the Slovenian Research Agency (research core funding No. (P1-0390 and P1-0005) and the project (J1-9176).

Conflicts of Interest: The authors declare no conflict of interest.

\section{References}

1. Simons, K.; Ikonen, E. How cells handle cholesterol. Science 2000, 290, 1721-1726. [CrossRef]

2. Cerqueira, N.M.; Oliveira, E.F.; Gesto, D.S.; Santos-Martins, D.; Moreira, C.; Moorthy, H.N.; Ramos, M.J.; Fernandes, P.A. Cholesterol biosynthesis: A mechanistic overview. Biochemistry 2016, 55, 5483-5506. [CrossRef] [PubMed]

3. Ačimovič, J.; Rozman, D. Steroidal triterpenes of cholesterol synthesis. Molecules 2013, 18, $4002-4017$. [CrossRef] [PubMed]

4. Mitsche, M.A.; McDonald, J.G.; Hobbs, H.H.; Cohen, J.C. Flux analysis of cholesterol biosynthesis in vivo reveals multiple tissue and cell-type specific pathways. eLife 2015, 4, 1-21. [CrossRef]

5. Belič, A.; Pompon, D.; Monostory, K.; Kelly, D.; Kelly, S.; Rozman, D. An algorithm for rapid computational construction of metabolic networks: A cholesterol biosynthesis example. Comput. Biol. Med. 2013, 43, 471-480. [CrossRef]

6. Skubic, C.; Rozman, D. Sterols from the post-lanosterol part of cholesterol synthesis: Novel signaling players. In Mammalian Sterols: Novel Biological Roles of Cholesterol Synthesis Intermediates, Oxysterols and Bile Acids; Rozman, D., Gebhardt, R., Eds.; Springer International Publishing: Cham, Switzerland, 2020. [CrossRef]

7. Porter, F.D.; Herman, G.E. Malformation syndromes caused by disorders of cholesterol synthesis. J. Lipid Res. 2011, 52, 6-34. [CrossRef]

8. Hubler, Z.; Allimuthu, D.; Bederman, I.; Elitt, M.S.; Madhavan, M.; Allan, K.C.; Shick, H.E.; Garrison, E.; Karl, M.T.; Factor, D.C.; et al. Accumulation of 8,9-unsaturated sterols drives oligodendrocyte formation and remyelination. Nature 2018, 560, 372-376. [CrossRef]

9. Santori, F.R.; Huang, P.; Van De Pavert, S.A.; Douglass, E.F.; Leaver, D.J.; Haubrich, B.A.; Keber, R.; Lorbek, G.; Konijn, T.; Rosales, B.N.; et al. Identification of natural ligands that regulate the development of lymphoid cells. Cell Metab. 2015, 21, 286-297. [CrossRef]

10. Chen, L.; Ma, M.Y.; Sun, M.; Jiang, L.Y.; Zhao, X.T.; Fang, X.X.; Lam, S.M.; Shui, G.H.; Luo, J.; Shi, X.J.; et al. Endogenous sterol intermediates of the mevalonate pathway regulate HMGCR degradation and SREBP-2 processing. J. Lipid Res. 2019, 60, 1765-1775. [CrossRef]

11. Griffiths, W.J.; Abdel-Khalik, J.; Yutuc, E.; Morgan, A.H.; Gilmore, I.; Hearn, T.; Wang, Y. Cholesterolomics: An update. Anal. Biochem. 2017, 524, 56-67. [CrossRef]

12. Murphy, R.C.; Axelsen, P.H. Mass spectrometric analysis of long-chain lipids. Mass Spectrom. Rev. 2011, 30, 579-599. [CrossRef] [PubMed]

13. Dias, I.H.K.; Wilson, S.R.; Roberg-Larsen, H. Chromatography of oxysterols. Biochimie 2018, 153, 3-12. [CrossRef] [PubMed]

14. Ai, J. Rapid measurement of free phytosterols in tobacco by short-column gc/ms/ms. j. Agric. Food Chem. 1997, 45, 3932-3935. [CrossRef]

15. Toivo, J.; Piironen, V.; Kalo, P.; Varo, P. Gas chromatographic determination of major sterols in edible oils and fats using solid-phase extraction in sample preparation. Chromatographia 1998, 48, 745-750. [CrossRef]

16. Acimovic, J.; Lövgren-Sandblom, A.; Monostory, K.; Rozman, D.; Golicnik, M.; Lutjohann, D.; Björkhem, I. Combined gas chromatographic/mass spectrometric analysis of cholesterol precursors and plant sterols in cultured cells. J. Chromatogr. B Anal. Technol. Biomed. Life Sci. 2009, 877, 2081-2086. [CrossRef] 
17. Moreau, R.A.; Nyström, L.; Whitaker, B.D.; Winkler-Moser, J.K.; Baer, D.J.; Gebauer, S.K.; Hicks, K.B. Phytosterols and their derivatives: Structural diversity, distribution, metabolism, analysis, and health-promoting uses. Prog. Lipid Res. 2018, 70, 35-61. [CrossRef]

18. Baila-Rueda, L.; Cenarro, A.; Cofán, M.; Orera, I.; Barcelo-Batllori, S.; Pocoví, M.; Ros, E.; Civeira, F.; Nerín, C.; Domeno, C. Simultaneous determination of oxysterols, phytosterols and cholesterol precursors by high performance liquid chromatography tandem mass spectrometry in human serum. Anal. Methods 2013, 5, 2249-2257. [CrossRef]

19. Cañabate-Díaz, B.; Segura Carretero, A.; Fernández-Gutiérrez, A.; Belmonte Vega, A.; Garrido Frenich, A.; Martínez Vidal, J.L.; Duran Martos, J. Separation and determination of sterols in olive oil by HPLC-MS. Food Chem. 2007, 102, 593-598. [CrossRef]

20. Rocco, A.; Fanali, S. Analysis of phytosterols in extra-virgin olive oil by nano-liquid chromatography. J. Chromatogr. A 2009, 1216, 7173-7178. [CrossRef]

21. Carretero, A.S.; Carrasco-Pancorbo, A.; Cortacero, S.; Gori, A.; Cerretani, L.; Fernández-Gutiérrez, A. A simplified method for HPLC-MS analysis of sterols in vegetable oil. Eur. J. Lipid Sci. Technol. 2008, 110, 1142-1149. [CrossRef]

22. Kim, D.; Park, J.B.; Choi, W.-K.; Lee, S.J.; Lim, I.; Bae, S.K. Simultaneous determination of $\beta$-sitosterol, campesterol, and stigmasterol in rat plasma by using LC-APCI-MS/MS: Application in a pharmacokinetic study of a titrated extract of the unsaponifiable fraction of Zea mays L. J. Sep. Sci. 2016, 39, 4060-4070. [CrossRef]

23. McDonald, J.G.; Smith, D.D.; Stiles, A.R.; Russell, D.W. A comprehensive method for extraction and quantitative analysis of sterols and secosteroids from human plasma. J. Lipid Res. 2012, 53, 1399-1409. [CrossRef] [PubMed]

24. Gaudin, M.; Imbert, L.; Libong, D.; Chaminade, P.; Brunelle, A.; Touboul, D.; Laprévote, O. Atmospheric pressure photoionization as a powerful tool for large-scale lipidomic studies. J. Am. Soc. Mass Spectrom. 2012, 23, 869-879. [CrossRef]

25. Abidi, S.L. Chromatographic analysis of plant sterols in foods and vegetable oils. J. Chromatogr. A 2001, 935, 173-201. [CrossRef]

26. McDonald, J.G.; Thompson, B.M.; McCrum, E.C.; Russell, D.W. Extraction and analysis of sterols in biological matrices by high performance liquid chromatography electrospray ionization mass spectrometry. Methods Enzymol. 2007, 432, 145-170. [CrossRef]

27. Marchand, D.H.; Croes, K.; Dolan, J.W.; Snyder, L.R.; Henry, R.A.; Kallury, K.M.R.; Waite, S.; Carr, P.W. Column selectivity in reversed-phase liquid chromatography. VIII. Phenylalkyl and fluoro-substituted columns. J. Chromatogr. A 2005, 1062, 65-78. [CrossRef] [PubMed]

28. Honda, A.; Miyazaki, T.; Ikegami, T.; Iwamoto, J.; Yamashita, K.; Numazawa, M.; Matsuzaki, Y. Highly sensitive and specific analysis of sterol profiles in biological samples by HPLC-ESI-MS/MS. J. Steroid Biochem. Mol. Biol. 2010, 121, 556-564. [CrossRef]

29. Lorbek, G.; Perše, M.; Horvat, S.; Björkhem, I.; Rozman, D. Sex differences in the hepatic cholesterol sensing mechanisms in mice. Molecules 2013, 18, 11067-11085. [CrossRef]

30. Urlep, Ž.; Lorbek, G.; Perše, M.; Jeruc, J.; Juvan, P.; Matz-Soja, M.; Gebhardt, R.; Björkhem, I.; Hall, J.A.; Bonneau, R.; et al. Disrupting hepatocyte Cyp51 from cholesterol synthesis leads to progressive liver injury in the developing mouse and decreases RORC signalling. Sci. Rep. 2017, 7, 1-13. [CrossRef]

Sample Availability: Samples of the compounds sterol standards available at Avanti Polar Lipids (Alabaster, AL, USA) and cell line samples are available from the authors.

(C) 2020 by the authors. Licensee MDPI, Basel, Switzerland. This article is an open access article distributed under the terms and conditions of the Creative Commons Attribution (CC BY) license (http://creativecommons.org/licenses/by/4.0/). 